\title{
Desenvolvimento de Objetos Educacionais para Medidas Elétricas
}




\section{Desenvolvimento de Objetos Educacionais para Medidas}

\section{Elétricas}

Trabalho de conclusão de curso apresentado à Coordenação do Curso de Especialização Tecnologias no Ensino Superior como requisito parcial para obtenção de título de Especialista em Tecnologias no Ensino Superior.

Orientador

Prof. Ana Maria Beltran Pavani

Coordenação Central de Educação a Distância Curso de Especialização Tecnologias no Ensino Superior 
Todos os direitos reservados. É proibida a reprodução total ou parcial do trabalho sem autorização do autor, do orientador e da universidade.

\section{David Martins Vieira}

Graduado em Engenharia Elétrica pela PUC-RIO em 1977. Professor horista do DEE da PUC-RIO, da disciplina Eletrotécnica Geral, de março de 1978 a dezembro de 1997 e de teoria de Eletrotécnica Geral, de agosto de 1998 até o momento. Trabalhou na VARIG S.A, de julho de 1987 a setembro de 1997, como engenheiro do Departamento de Instalação e Manutenção de Equipamentos de Telecomunicações e como Coordenador de treinamento dos Técnicos de Manutenção. Exerceu na UERJ (Universidade do Estado do Rio de Janeiro) os cargos de Chefe dos Laboratórios de Engenharia Elétrica (1978 a 1987), Coordenador do Ciclo Básico da Engenharia (1997 a 1999), vice-diretor "protempore" da Faculdade de Engenharia da UERJ ((1997 a 1999), entre outros. Atualmente é professor, na UERJ de disciplinas de laboratório da área de Eletrotécnica e professor, na PUC da disciplina Eletrotécnica Geral. 


\section{Dedicatória}

À minha esposa Ana Lucia e à minha filha Mariana, pela imensa paciência e compreensão que tiveram para comigo, durante a preparação deste trabalho. 


\section{Agradecimentos}

À minha orientadora, profa. Ana Pavani, pela disponibilidade de seu tempo e pelo interesse e atenção dedicados a este trabalho e à Vanessa Palomo Lima e ao Daniel Bindes Pereira, da Equipe Técnica do Maxwell, pela ajuda na preparação dos Objetos Educacionais. 


\section{Resumo}

Desenvolvimento de Objetos Educacionais para Medidas Elétricas é um trabalho que procura estabelecer entre um aluno de qualquer área da engenharia e o objeto a ser estudado, no caso Medidas Elétricas, uma relação que o afaste de uma linha pedagógica instrucional, para uma linha construtivista-interacionista. Para isto utiliza como ferramenta principal as Tecnologias da Informação e da Comunicação (TIC), através do ambiente Maxwell, disponibilizado pelo DEE da PUC e há muito tempo sendo utilizado, com excelentes resultados, pelos alunos da graduação. Este projeto tem um objetivo muito claro que é o de apoiar a aprendizagem das disciplinas que dependem de medidas e de instrumentação e se utiliza de elementos da disciplina Eletrotécnica Geral, lecionada há vários anos pelo autor, como referência, devido à variedade de desafios que a mesma apresenta e, portanto, propícia ao desenvolvimento de objetos, com aplicações às demais disciplinas.

\section{Palavras-chave:}

Objetos Educacionais, Medidores Elétricos, Transdutores, Medidores Analógicos, 


\section{SUMÁRIO}

Será feita depois (sugestão) 
Aprendemos na escola muitos conceitos, muitos conhecimentos, mas todos dispersos... As escolas acumularam saberes, mas não são capazes de organizá-los. 


\section{Introdução}

A declaração feita por um dos maiores sociólogos, antropólogos e filósofos vivos, Edgard Morin, compilada parcialmente na epígrafe deste trabalho, foi feita no encontro internacional Educação 360, no dia 6 de setembro, deste ano, no Rio de Janeiro. A declaração completa foi:

"Aprendemos na escola muitos conceitos, muitos conhecimentos, mas todos dispersos. Precisamos desenvolver um modelo educacional que ligue esses conhecimentos, que os coloque em perspectiva. As escolas acumularam saberes, mas não são capazes de organizá-los."

Essa crítica não se refere a um curso especifico do primeiro grau, segundo ou curso superior, mas a toda a estrutura de ensino, portanto atinge também ao professor, o qual pode entender a afirmativa como uma forma de desafio ao seu trabalho e fazê-lo repensar o ato de educar.

Este trabalho tem um objetivo muito claro de apoiar a aprendizagem nas disciplinas que dependem de medidas e utilização de instrumentação. Para isto se procurou criar alguns Objetos Educacionais sobre o assunto, utilizando fotos, vídeos, imagens, links, disponibilizados através do ambiente Maxwell, já amplamente usado por alunos de diversos cursos de engenharia elétrica da PUCRio.

Uma das disciplinas a qual este projeto pretende atender é Eletrotécnica Geral (ENG-1018) e Laboratório de Eletrotécnica Geral (ENG-1919), cujas aulas teóricas vêm sendo ministradas por este professor desde 1999. Devido às suas peculiaridades e a de seus alunos, as quais serão enumeradas e analisadas mais adiante, será uma das disciplinas nas quais se pretende aplicar e avaliar os resultados destes Objetos. 


\section{Características da disciplina Eletrotécnica Geral}

Esta disciplina é oferecida todos os semestres devido ao grande número de alunos inscritos, em média 180 por semestre, tendo atingido, por, duas vezes nos últimos três anos, o total de 215, como ocorreu no primeiro semestre de 2014.

\subsection{Perfil dos alunos}

Eletrotécnica Geral ( teoria e laboratório) é oferecida para vários cursos de engenharia, como disciplina de caráter obrigatório, e cujos cursos são relacionados a seguir: Civil, Mecânica, Produção, Química, Petróleo e Ambiental. É oferecida, também, como optativa para algumas áreas da elétrica, como por exemplo, Nanotecnologia.

Para que se tenha uma visão melhor da distribuição curso/aluno, a cada início de semestre é feito um levantamento, no primeiro dia de aula, em cada uma das três turmas, através de uma folha de presença, assinada pelos alunos, em que estes informam sua matrícula e o curso que estão fazendo. Foi utilizado um universo de 300 alunos que cursaram este ano, obtendo-se os seguintes valores:

\begin{tabular}{|lc|}
\multicolumn{1}{|l}{ Cursso } & Alunos (\%) \\
\hline Produção & 37 \\
\hline Civil & 22 \\
\hline Mecânica & 16 \\
\hline Química & 10 \\
\hline Petróleo & 6,0 \\
\hline Ambiental & 5,0 \\
\hline Outros & 4,0 \\
\hline
\end{tabular}




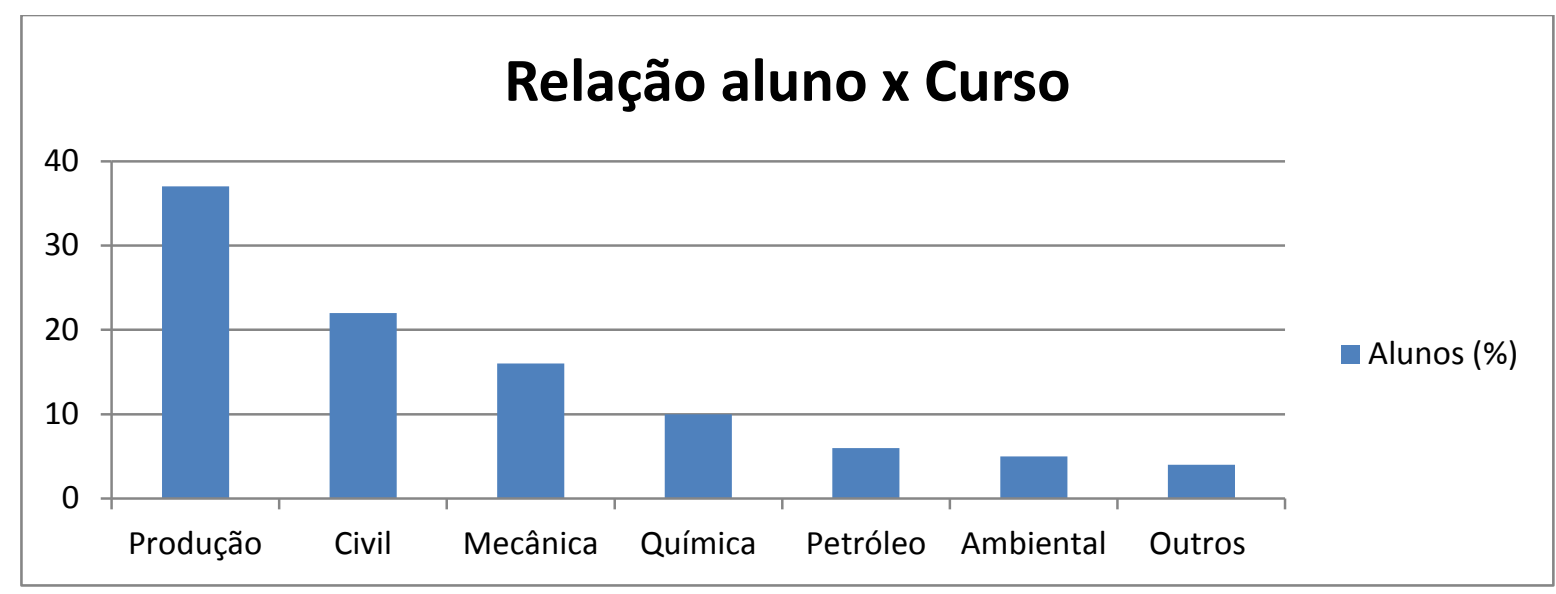

Pelo gráfico mostrado anteriormente, podemos observar a variedade de alunos de cursos distintos e a desproporcional distribuição. Por serem de áreas diferentes, estes alunos têm interesses diferentes e se mostram mais interessados pelo assunto exposto quando é feita uma relação, através de exemplos em aula, com a sua área de interesse de formação, ou quando se trata de algum assunto do seu dia a dia, como por exemplo, falar de Eletrostática, utilizando exemplos de ocorrências recentes de descargas atmosféricas, sobre imóveis ou pessoas, noticiadas pelos meios de comunicação.

\subsection{Períodos de Créditos Cursados pelos Alunos}

Além da diversidade de áreas, os alunos cursam períodos de créditos bem diversos, o que também dificulta a apresentação dos temas nas aulas e a participação deles nas discussões, pois alguns acabaram de cursar a disciplina oferecida pelo Departamento de Física, no terceiro período, que é pré-requisito para Eletrotécnica Geral, enquanto outros já estão nos períodos finais, às vésperas de suas formaturas e sentem, portanto, mais dificuldades em acompanhar o ritmo da disciplina. Isto ocasionou uma mudança na sequência da exposição dos temas do programa da disciplina, obrigando a que se faça uma rápida revisão dos tópicos principais, abordados na disciplina que é pré-requisito de Eletrotécnica.

Num simples levantamento pelo número de matrícula nas pautas das turmas do período 2014-2, para verificar o percentual de alunos que estão no quarto 
semestre, que é o período de créditos indicado para cursar a disciplina, construiuse a seguinte tabela:

\begin{tabular}{|ll|}
\hline $\mathbf{4}$ & Alunos Inscritos (\%) \\
\hline $\mathbf{5}$ & 11 \\
\hline $\mathbf{6}$ & 16,2 \\
\hline $\mathbf{7}$ & 32,4 \\
\hline $\mathbf{8}$ & 12,7 \\
\hline $\mathbf{9}$ & 11,6 \\
\hline $\mathbf{1 0}$ & 4,0 \\
\hline Acima de $\mathbf{1 0}$ & 4,6 \\
\hline
\end{tabular}

Foi usado um universo de 177 alunos, para obtenção dos percentuais, e pudemos verificar, usando o gráfico construído a partir da tabela, que a maior parte dos alunos inscritos já cursou mais de seis semestres antes de se inscreverem na disciplina de Eletrotécnica, quando o ideal seria que a cursassem após o quarto período de créditos, logo após cursarem as disciplinas FIS 1006 e MAT 1152, que dão a base necessária para o entendimento dos temas abordados posteriormente. 


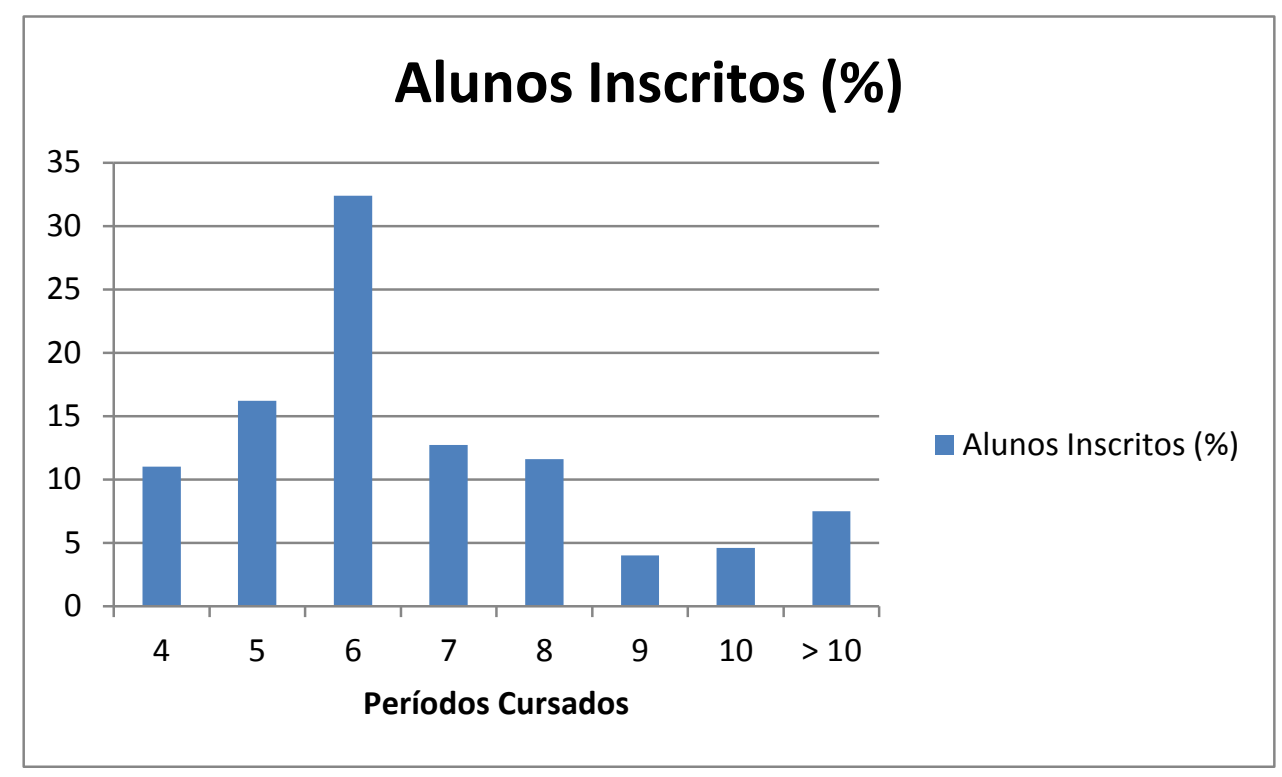

O que ocorre, porém é que, segundo comentários de alunos consultados a cada início de semestre, uma das disciplinas pré-requisito ( FIS 1006), é difícil e tem percentual elevado de reprovação, fazendo com que se atrasem ou protelem a inscrição na mesma.

\subsection{Carga horária}

A disciplina tem 2 créditos, o que corresponde a duas horas semanais de aula. Durante o semestre correspondem, em média, a 18 aulas onde está incluída também, a carga horária de quatro testes, sendo três obrigatórios e um teste final para os alunos que não foram aprovados, após os três primeiros, conforme o critério da disciplina.

Os alunos devem inscrever-se, também, na disciplina Laboratório de Eletrotécnica Geral (ENG-1019), cuja carga horária é de uma hora semanal e tem como objetivo fazer com que os conceitos apresentados aos alunos nas aulas teóricas presenciais sejam colocados em prática. Nestas aulas são necessários, além dos conhecimentos adquiridos nas aulas teóricas, conhecimentos sobre equipamentos de medidas, métodos de avaliação e registro das leituras, além de conhecimentos sobre a simbologia utilizada nesses equipamentos. 
Para que os alunos possam realizar as experiências previstas nas aulas práticas é necessário que haja uma coordenação entre os assuntos a serem abordados nas aulas teóricas, de tal forma que tenham condições de entenderem o que está sendo proposto nas aulas práticas.

Isto nem sempre é possível, pois devido ao grande número de alunos, e devido às turmas de laboratório não poderem ter mais de vinte alunos, acarretam um número grande das mesmas, entre 7 e 8, distribuídas durante a semana. Quando há um feriado ou ponto facultativo coincidindo com o horário de uma turma, ocorrem defasagens inevitáveis entre a teoria e a prática.

\subsection{Técnicas de Treinamento e Material Didático}

As aulas teóricas têm sido ministradas, até o momento, sob a forma presencial tradicional, onde as tentativas para transmissão do conhecimento utilizam muito poucos recursos das TICs. É utilizado o "quadro e giz" na maior parte do tempo.

Curiosamente, algumas vezes foram feitas observações, geralmente no início do semestre, sobre o uso do Power Point. Alguns alunos afirmaram que o seu uso em aula, tornava a apresentação dos temas muito rápida, volumosa e de difícil assimilação. A forma de apresentação oral e o desenvolvimento utilizando o quadro, nas deduções de expressões matemáticas, é, segundo eles, muito mais fácil de acompanhar e de assimilar.

O sistema SAU é utilizado com uma ferramenta, não só para lançamento dos graus, mas permite também a comunicação, via $e$-mail, com os alunos, onde eventualmente são feitas algumas comunicações, sobre horários para tirar dúvidas, quando se aproxima a data de algum teste. Também foi usado em poucas ocasiões para envio de exercícios para os alunos.

Outro problema ocasionado pelo fato dos alunos pertencerem à áreas de engenharia diversas é o referente à bibliografia adotada, pois existem algumas obras sobre o assunto, direcionadas para áreas específicas, referenciados como 
livro de Eletrotécnica para cursos de engenharia civil ou para cursos de engenharia elétrica ou ainda, para cursos de engenharia mecânica.

Para tentar contornar esse problema vem sendo preparado um material complementar, sobre as notas de aula, numa linguagem que seja acessível a todos.

Esse material é disponibilizado pelo professor aos alunos, que por sua vez fazem cópias, à medida que os assuntos da disciplina vão sendo apresentados em aula. Paralelamente a isso é indicada uma bibliografia, com várias obras, de modo que os alunos utilizem aquelas mais afins à suas áreas de formação.

\subsection{Proposta de um Projeto Pedagógico}

Os dados aqui apresentados, sobre a disciplina Eletrotécnica Geral, têm muitos pontos em comum com outras disciplinas da graduação e representam um desafio no sentido de se fazer um projeto pedagógico que altere esse cenário, utilizando as ferramentas já em uso nesta universidade, como as disponibilizadas pelo ambiente Maxwell. Além disso, os tópicos sobre Medidas Elétricas e Transdutores abordados neste trabalho são importantes para outras disciplinas oferecidas pelo Departamento de Engenharia Elétrica como Circuitos Elétricos, Conversão Eletromecânica de Energia, Eletrônica Analógica e Controles e Servomecanismos. Outro aspecto a ser levado em consideração é que não há uma disciplina de Medidas Elétricas, o que faz com que os alunos cheguem despreparados para as referidas disciplinas, prejudicando o desempenho dos mesmos.

Primeiramente se pretende desenvolver e utilizar recursos tecnológicos no processo de ensino-aprendizagem, como complemento às atividades didáticas presenciais da disciplina Eletrotécnica Geral e de outras disciplinas correlatas.

\subsection{Etapas a serem cumpridas:}

1- Criação de Objetos Educacionais, usando o ambiente Maxwell, já existente, na forma de textos breves sobre assuntos de Medidas Elétricas. Os textos conterão fotos, imagens, links, etc e serão disponibilizados aos alunos no formato pdf. Eles servirão de referência ao estudo dos tópicos e poderão ser "baixados" e/ou impressos pelos alunos. 
2- Criação de objetos Educacionais sob a forma de vídeo-aulas, apresentando conteúdos onde o vídeo possa proporcionar melhores resultados para o aprendizado de práticas de laboratório.

3- Criação de Objetos Educacionais com animações e, ou interatividade, dentro de um ambiente hipermídia, com os quais os alunos possam interagir on-line.

\subsection{Metodologia do trabalho:}

1- Primeiro passo: elaboração dos conteúdos textuais cobrindo os itens apresentados a seguir;

2- Segundo passo: definição da granularidade dos Objetos Educacionais em vídeo e, ou com animações e interatividade. No momento, considera-se que serão quatro, um para cada grande tópico a seguir;

3- Terceiro passo: elaboração dos roteiros dos Objetos Educacionais, redigindo os textos e especificando os conteúdos multimídia (com seus roteiros e características), que serão incluídos neste trabalho.

4- Quarto passo: especificação dos Objetos Multimídia à Equipe Técnica do Maxwell que os programará;

5- Quinto passo: gravação dos vídeos que forem definidos;

6- Sexto passo: teste e homologação dos Objetos Educacionais;

7- Sétimo passo: passagem do texto e dos Objetos Educacionais à Equipe de Biblioteconomia para catalogação e disponibilização no Maxwell. Farão parte dos metadados os títulos (em português e inglês), o resumo (em português e inglês) e as palavras-chave (em português e inglês), além do formato digital, o tamanho do arquivo, o nível de acesso e as especificações de acessibilidade.

\subsection{Conteúdos a serem abordados pelos Objetos:}

1- Definições de Medição e Avaliação de Resultados

2- Transdutores usados em Instrumentação

3- Tipos de Instrumentos de Medida 3.1- Analógicos Eletromecânicos 


\section{2- Analógicos Eletrônicos}

\section{3- Digitais}

4- Osciloscópio:

4.1- Analógico

\section{2- Digital}

O foco do trabalho será direcionado para medidas elétricas utilizando osciloscópios, portanto, o item 5 será mais detalhado em relação aos demais, consistindo dos seguintes itens:

1- Diagrama em blocos de osciloscópios analógicos;

2- Tipos de osciloscópios analógicos;

3- Pontas de prova e transdutores;

4- Funções, técnicas de medida e aplicações;

5- Osciloscópios digitais, diagrama em blocos;

6- Sistemas de aquisição de dados de osciloscópios digitais;

7- Funções, técnicas de medida e aplicações.

\subsection{Organização do trabalho:}

O trabalho será apresentado em forma textual, conforme as normas da CCEAD, com anexos. O primeiro anexo será o texto que será disponibilizado aos alunos para leitura linear. Os demais serão os roteiros dos Objetos Educacionais.

Além disto, serão gerados os programas referentes a cada um dos Objetos Educacionais para uso on-line. 


\section{Desenvolvimento do Projeto}

Dos conteúdos a serem abordados pelos Objetos foram desenvolvidos os textos dos seguintes temas:

1- Definições de Medição e Avaliação de Resultados

2- Transdutores usados em Instrumentação

Para o primeiro item foi preparado um material didático, com fotos dos equipamentos de medidas usados pelos alunos nas aulas práticas, conforme mostra a ilustração de um trecho a seguir e colocado integralmente nos anexos deste trabalho:

$\mathrm{Na}$ foto abaixo, além da informação do medidor dada pela letra $\mathbf{A}$, ou seja, mede Amperes, existem mais cinco informações importantes, colocadas abaixo e à esquerda do visor. No caso as informações são as seguintes:

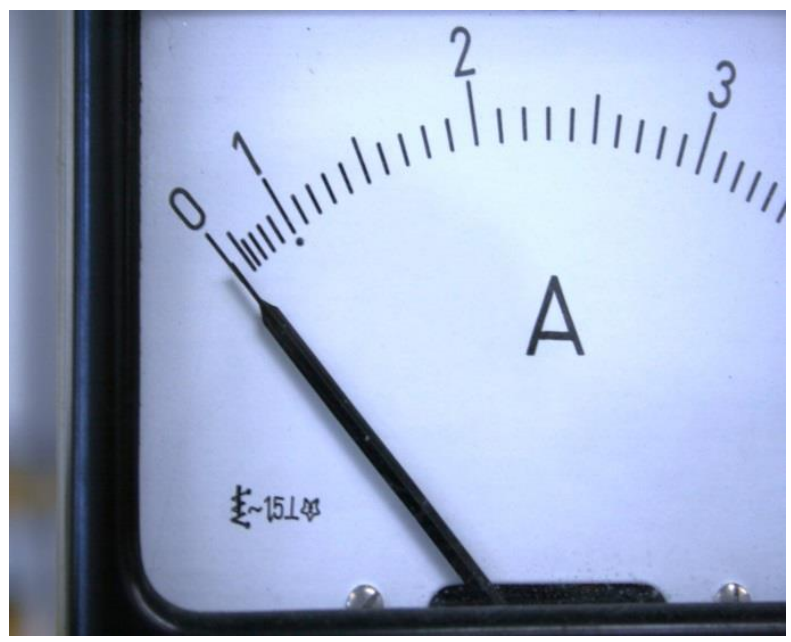

Este material pode ser acessado pelo aluno, diretamente, caso esteja interessado em estudar o tema ou através de links disponibilizados pelo ambiente Maxwell, quando estiver acessando algum Objeto e desejar conhecer mais detalhes sobre o assunto, usando uma abordagem simples, de maneira que possa ser compreendido por alunos que estejam cursando outras disciplinas. 
Os Objetos escolhidos para serem acessados pelos alunos foram os seguintes:

-Transdutor Termopar

- Transdutor LDR

- Transdutor de Campo Magnético

- Transdutor Termoelétrico

-Transdutor Fotovoltaico

- Transdutor Piezoelétrico

A título de ilustração, mostramos a seguir um trecho material preparado sobre o Transdutor de Campo Magnético.

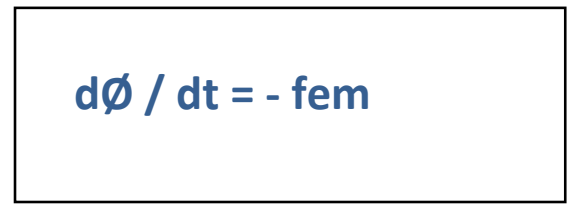

O sinal negativo da fem (força eletromotriz) indica que a tensão gerada terá uma polaridade tal que criará uma corrente, caso o circuito esteja fechado, que produzirá um fluxo magnético $(\varnothing)$, contrário ao que o criou.

Vemos a seguir uma ilustração de um captor de energia sonora (microfone), onde nos terminais da bobina, que se move com o choque das ondas sonoras (força $F$ ) sobre 0 cone, surge uma fem proporcional ao fluxo cortado, que aparece nos terminais A, B.

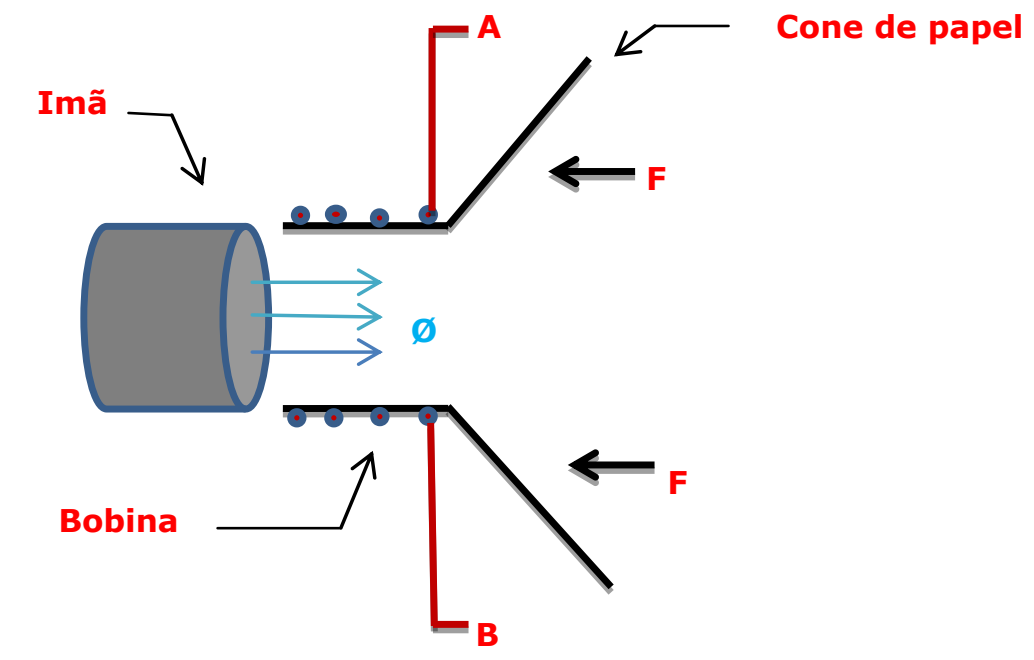


Além desse material, foram preparados pequenos vídeos, com duração máxima de dois minutos, para cada um dos objetos citados anteriormente. Neles se procurou mostrar os efeitos apontados nos textos teóricos, porém utilizando materiais do dia a dia das pessoas, na tentativa de integrar saberes e mostrar as diversas aplicações da tecnologia na vida das pessoas.

Como foi dito anteriormente, o ambiente utilizado foi o Maxwell, que é acessado, entre outros, através do endereço http://www.maxwell.vrac.puc-

rio.br/eletricaonline/inicio.php mostrado abaixo, podendo também ser acessado pelo portal puc-rio:

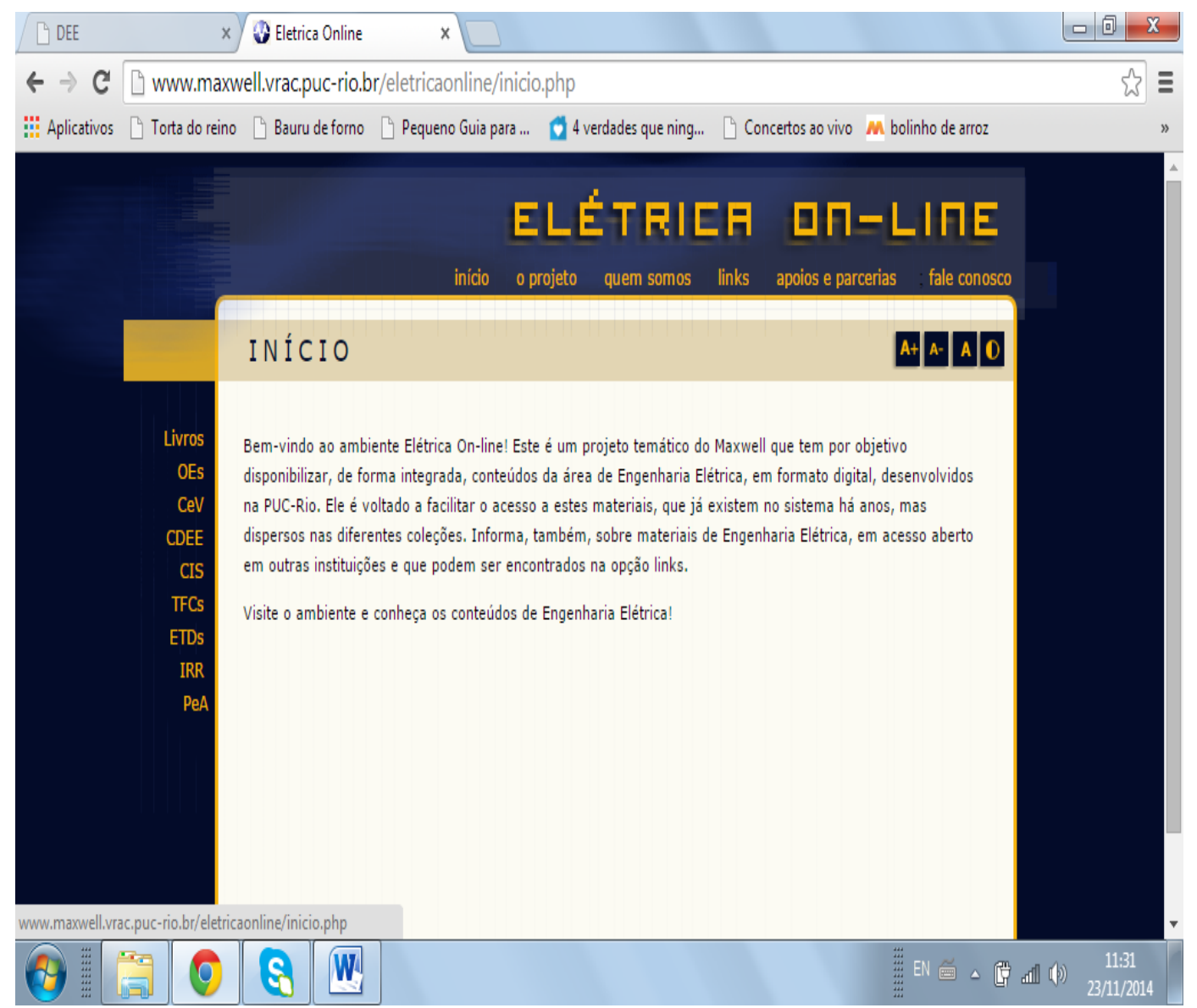

A seguir transcrevemos o Texto apresentado no endereço acima mostrando o que é o ambiente Elétrica On-line, onde está inserido o Maxwell.

O Elétrica On-line é um ambiente desenvolvido no Sistema Maxwell para oferecer de forma integrada os materiais, todos em formato digital, da área de Engenharia Elétrica na PUC-Rio. Os materiais são das mais diversas naturezas. 
Há aqueles que são educacionais e voltados ao nível de graduação; eles são encontrados nos Livros Interativos de Engenharia Elétrica e na Série Objetos Educacionais. Ambos estão em permanente crescimento.

Outros conteúdos são produtos do processo educacional; eles estão disponibilizados nas ETDs - Electronic Theses and Dissertations, que apresentam as teses (nivel de doutorado) e as dissertações (nível de mestrado) do Programa de Pós-Graduação em Engenharia Elétrica e nos TFCs - Trabalhos de Fim de Curso que contêm os Projetos de Graduação em Engenharia Elétrica. Cabe ressaltar que houve digitalização retrospectiva das teses e dissertações originalmente apresentadas em papel e que, como consequência, a coleção está completa.

Um terceiro tipo é contido nas séries que disponibilizam artigos publicados originalmente em periódicos ou anais de congressos, e pre-prints com registros de pesquisas. Eles podem ser encontrados nas séries.

Em Elétrica On-line, estão, também, disponibilizados endereços de sites que contêm conteúdos de interesse à área de Engenharia Elétrica.

Como todos os materiais e referências aqui disponibilizados fazem parte do acervo contido no Maxwell, a atualização do ambiente Elétrica On-line se dá de forma automática, à medida que os conteúdos seguem seu fluxo normal de disponibilização no Sistema.

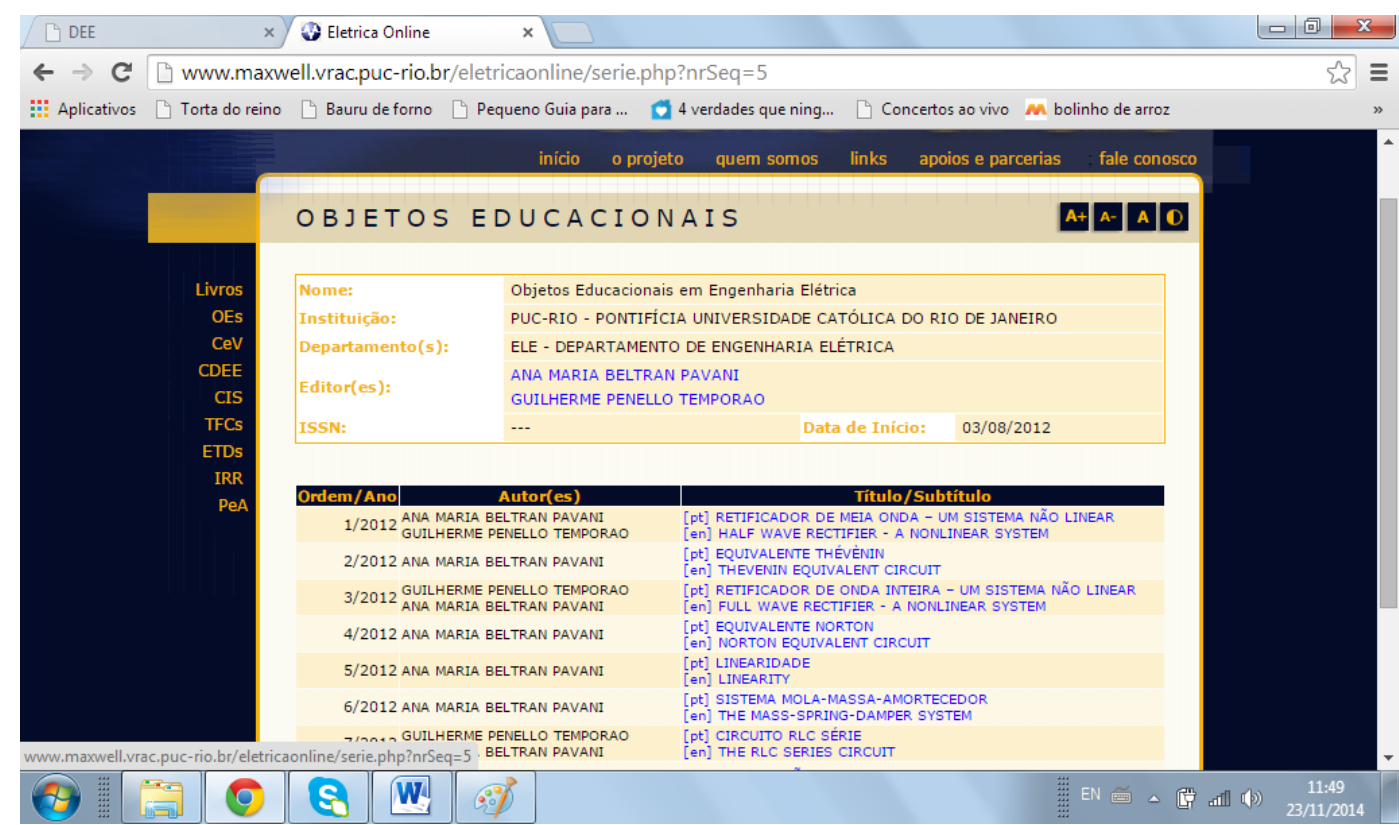


A tela de Objetos Educacionais é acessada ao se clicar em $O E s$, no lado esquerdo da tela, mostrado na figura acima, onde se pode ver, à direita, os vários tipos de Objetos e seus respectivos autores.

A interatividade entre os Objetos, os textos com informações mais detalhadas e os vídeos são garantidas através de links, localizados de forma a facilitar a navegação pelo aluno.

Podemos ver a seguir as telas dos objetos desenvolvidos em função deste trabalho.
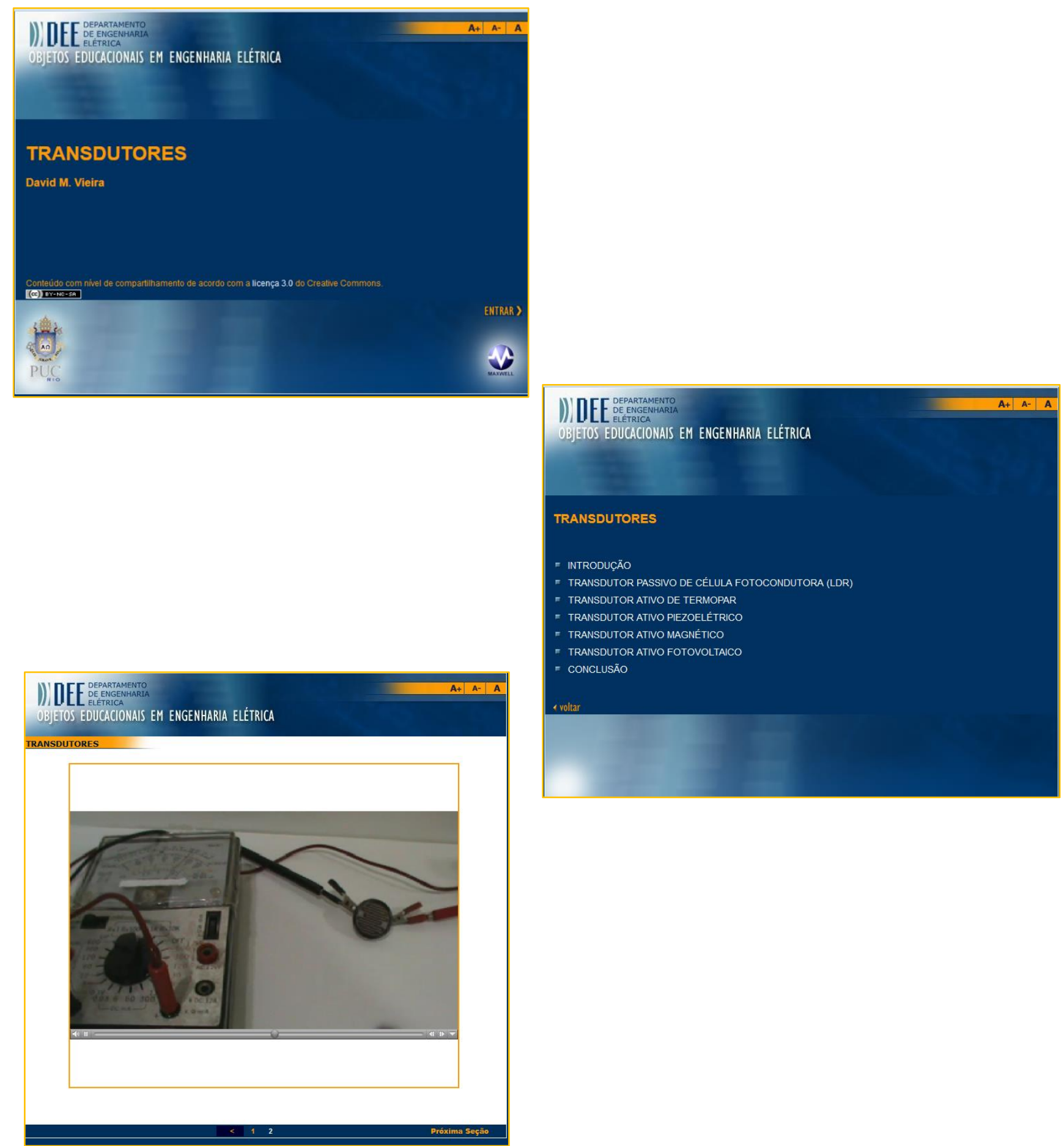


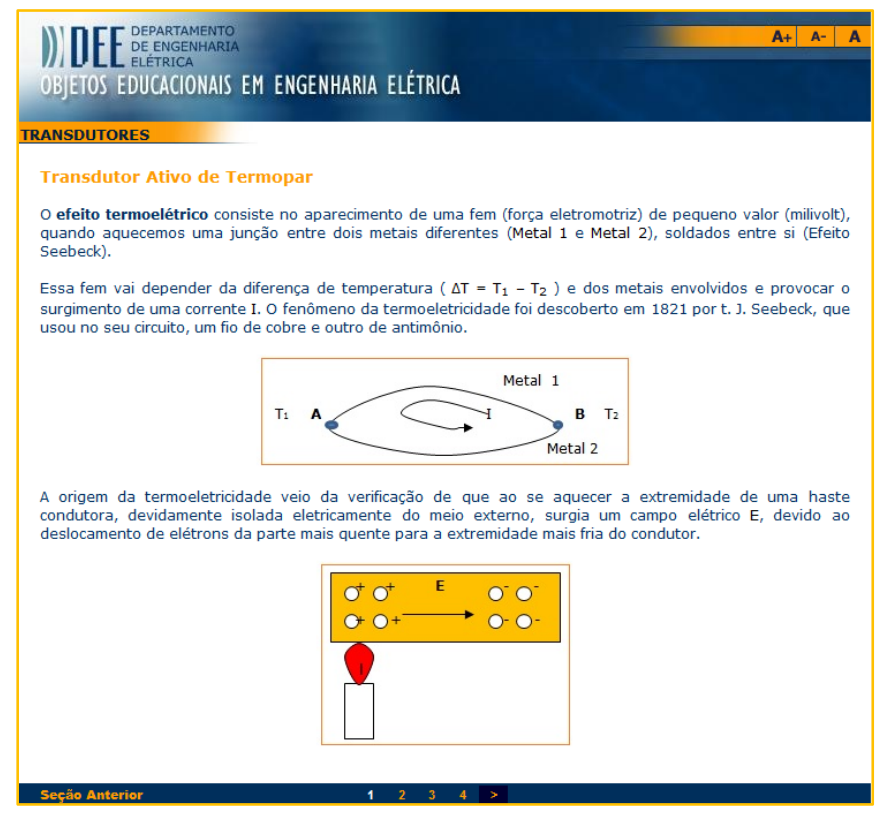

http://www.maxwell.vrac.puc -rio.br/teste/obj/ 
Conclusão:

Espera-se através deste trabalho atingir a meta de se poder utilizar, da melhor forma possível as Tecnologias da Informação e da Comunicação, através de um Design Pedagógico que integre o maior número possível de saberes, no processo de ensino-aprendizagem. 


\section{Referências Bibliográficas}

1. Helfrick, Albert. Instrumentação Eletrônica Moderna e Técnicas de Medição. Rio de Janeiro, Editora Prentice Hall do Brasil Ltda, 1994.

2. Vervloet, A. Werter. Eletrônica Industrial. Rio de Janeiro, LTC

3. Werneck, Marcelo. Transdutores e Interfaces. LTC Editora. 1996.

4. Fowler, Richard J. Eletricidade e Aplicações, vol. 1. São Paulo, Makron Books do Brasil, 1992

5. Medeiros, Solon. Fundamentos de Medidas Elétricas. Rio de Janeiro, LTC, 1981.

6. Torreira, Raul P.Instrumentos de Medição Elétrica. São Paulo: Hemus Livraria, 1978. 
Anexos 
Este tipo de erro não ocorre em instrumentos com mostrador digital, obviamente.

Outro tipo frequente de erro grosseiro deve-se ao chamado "efeito de carga" e que ocorre quando não se avalia o efeito da colocação do instrumento no circuito a ser medido. O instrumento passará a fazer parte do circuito, modificando-o e, portanto, modificando os valores esperados. 


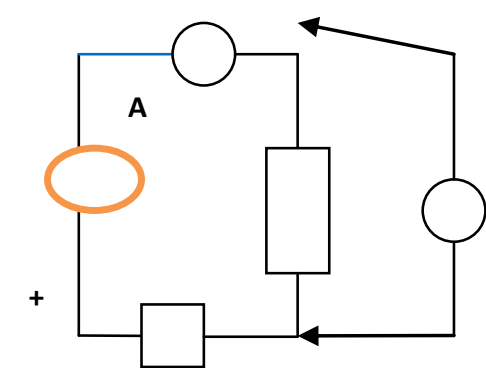

Deseja-se conhecer a tensão nos terminais

resistência interna do voltímetro for do

$\mathbf{R}_{\mathbf{2}}$

mesmo valor, a ponta de prova do

instrumento ao tocar no circuito, fará com

que o amperímetro mude a sua leitura, pois a resistência equivalente de $R_{1}$ com o voltímetro será igual a 5.000 ohms. Se for dividido o valor de V pelo valor de I, será achado um valor diferente de $R_{1}$.

Outro tipo de erro grosseiro muito comum ocorre quando se deseja medir um valor de resistência com um ohmímetro e não se ajusta a leitura para zero ohms, quando é feito contato direto entre as pontas de prova. Ao se juntar as duas pontas, está se 'informando' ao instrumento que a resistência que está sendo medida (curto entre as pontas) é zero.

Grande parte dos erros humanos ocorre devido ao desconhecimento, por parte do usuário, das características dos instrumentos. As principais vêm, geralmente, informadas no painel frontal do equipamento de medida. 
Na foto abaixo, além da informação do medidor dada pela letra A, ou seja, mede Amperes, existem mais cinco informações importantes, colocadas abaixo e à esquerda do visor. No caso, as informações

são as seguintes:

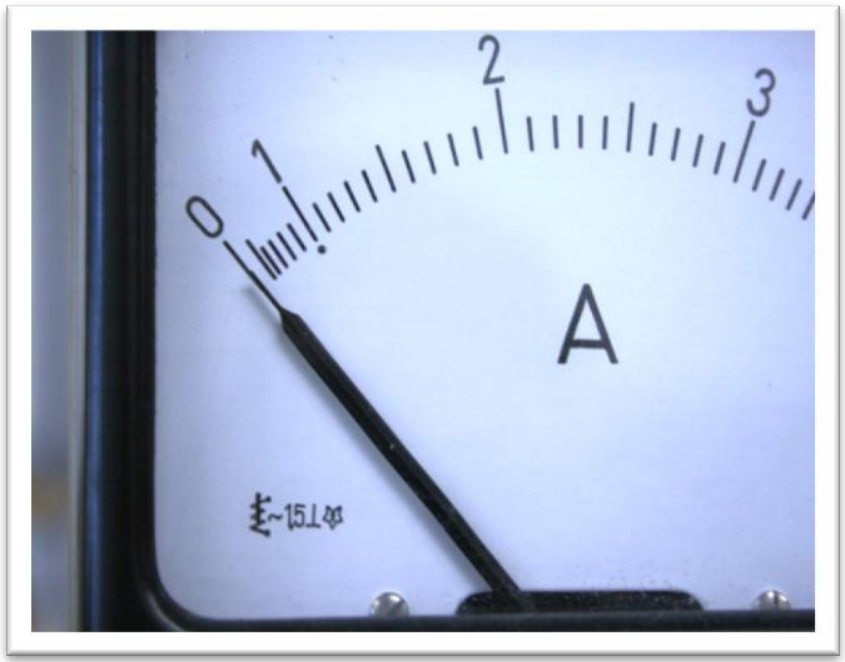

安 Instrumento do tipo Ferro Móvel: isto significa que lê grandezas senoidais ou contínuas. Significa, também que a escala numérica não é linear e sim, quadrática.

Deve-se, portanto, ter o cuidado ao se fazer leituras em que o ponteiro esteja entre dois traços quaisquer, pois dificulta a avaliação do valor medido.

( )Significa que está aferido para ler corrente alternada (monofásica). Se tivesse também o sinal _ significaria que está aferido para ler corrente contínua, visto que os instrumentos de ferro móvel são sensíveis aos dois tipos de corrente.

(1.5) significa que o equipamento tem uma classe de exatidão de $1.5 \%$. 
Significa que o instrumento deve ficar com o mostrador na vertical, ou seja, se o usuário, por

comodidade, colocá-lo na horizontal, a leitura apresentará um erro maior do que o informado.

A estrela com um algarismo no seu interior, no caso, $\mathbf{2}$, indica a sua tensão de ensaio à frequência industrial, é de 2.000 volts.

Por exemplo, se este amperímetro estivesse medindo de um equipamento conectado entre linha e neutro de uma fonte trifásica de $220 \mathrm{~V}$, e estivesse sobre a bancada do laboratório, no LAMAQ, por exemplo, a tensão entre a carcaça e o sistema ferro móvel de medida seria igual a 220 / V3, ou seja, 127 V. Portanto, essa tensão seria segura para o instrumento, que suporta até 2.000 volts.

Finalmente, os erros grosseiros são de inteira responsabilidade do operador e não podem ser tratados matematicamente. Para minimizá-los ou evitá-los é necessário repetir o trabalho de medição e principalmente, trabalhar com muita atenção.

\section{Erros Sistemáticos}

Esse tipo de erro ocorre devido à deficiência do método, do material utilizado ou da avaliação da medida do operador.

Abrangem os erros de construção ou aferição, que é dado pela qualidade do material utilizado, os erros ou imperfeições do observador e os da imperfeição dos métodos de medida.

Podemos dividi-los em três classes principais:

1. Instrumental: ocorre devido à ineficácia do instrumento, ao mau trato, ou a efeitos de sobrecargas nos mesmos. Por exemplo, num instrumento do tipo bobina móvel, um alongamento anormal na mola de torção, provocada por uma utilização inadequada pode resultar numa série de medidas erradas. 
2. Ambiental: os instrumentos são afetados pelo meio e interagem com ele. Isto inclui as condições no entorno da área onde é feito o ensaio. Por exemplo, se a temperatura ambiente, no local da medição, for elevada, os valores dos componentes do equipamento de medida podem sofrer variações que se refletirão nos valores medidos. Campos magnéticos também afetam medidores com peças móveis. Para diminuir tais efeitos deve-se consultar as informações do fabricante, tais como a temperatura recomendada para utilização, existência de blindagem magnética, proteção contra umidade, etc.

3. Observação: pessoas diferentes usando os mesmos equipamentos de medida para um mesmo conjunto de medidas não reproduzem necessariamente os mesmos resultados.

\section{Erros Aleatórios}

São erros devidos a causas desconhecidas. Ocorrem mesmo que todos os erros sistemáticos tenham sido levados em conta. São erros acidentais e de difícil eliminação. Quando todos os cuidados são tomados para a realização das medidas, a probabilidade deles ocorrerem é pequena. Quando ocorrem em experimentos de grande precisão, devem ser acompanhados de uma investigação minuciosa. Para compensar esse tipo de erro recomenda-se aumentar o número de leituras e da análise estatística para se obter a melhor aproximação do valor verdadeiro da grandeza que está sendo medida.

\section{1- Cálculo do Erro, Erro Absoluto, Erro Relativo}

Na norma ABNT NB- 278/73 encontramos as definições e conceitos oficiais sobre os erros dos Instrumentos Elétricos Indicadores.

$O$ erro é definido como a diferença algébrica entre o Valor Medido $\left(V_{m}\right)$ de uma grandeza e o verdadeiro, que é um valor ideal, supondo que nenhum tipo de erro incide na medição, ou seja, um valor esperado $\left(V_{e}\right)$.

$$
\mathrm{V}_{\mathrm{m}}-\mathrm{V}_{\mathrm{e}}=\Delta \mathrm{V}
$$

Valor Verdadeiro é o valor exato da medida de uma grandeza, obtido quando nenhum tipo de erro incide na medição. É a medida de uma amostra de um determinado número de medidas técnicas, usando o mesmo material e mantendo-se, na medida do possível, as mesmas condições ambientais.

É praticamente impossível eliminar todos os erros e encontrar um valor aceito como verdadeiro. Portanto, na falta de um valor Verdadeiro, aceita-se o valor de referência ou padrão $\left(V_{p}\right)$, que substitui o valor verdadeiro.

Pode-se também definir como erro, a diferença entre o Valor Medido $\left(V_{m}\right)$ e o Valor Padrão $\left(V_{p}\right)$, obtido através do método de referência construído na prática: 
$\mathrm{V}_{\mathrm{m}}-\mathrm{V}_{\mathrm{p}}=\Delta \mathrm{V}$

Assim o erro é definido, de uma forma geral, como: $\quad \Delta V=V_{m}-V_{p}=V_{m}-V_{e}$

Podemos então expressar o valor verdadeiro ou esperado $\left(\mathrm{V}_{\mathrm{e}}\right)$ como:

$\mathrm{V}_{\mathrm{m}}-\Delta \mathrm{V} \leq \mathrm{V}_{\mathrm{e}} \leq \mathrm{V}_{\mathrm{m}}+\Delta \mathrm{V}$

$\Delta V$ é chamado de limite superior do erro absoluto, limite máximo do erro absoluto ou "erro absoluto", simplesmente.

Se $V_{m}>V_{e}$, o erro é por excesso.

Se $V_{m}<V_{e}$, o erro é por falta.

A relação entre o erro absoluto $(\Delta V)$ e o valor verdadeiro $\left(V_{e}\right)$ é chamada de erro relativo $(\varepsilon)$ :

$\varepsilon=\Delta \mathrm{V} / \mathrm{V}_{\mathrm{e}}$

Para efeito de cálculo do erro relativo pode-se considerar, na maioria dos casos, o valor medido igual ao valor esperado, no denominador, tendo em vista que são muito próximos:

$\varepsilon=\Delta \mathrm{V} / \mathrm{V}_{\mathrm{m}}$

Podemos expressar o erro relativo na forma percentual:

$\varepsilon_{\%}=\left(\Delta \mathrm{V} / \mathrm{V}_{\mathrm{m}}\right) \times 100$ 



\section{Média Aritmética}

A análise de um conjunto de medidas de uma mesma grandeza, através de um tratamento estatístico, é uma prática recomendável, uma vez que permite determinar o o seu grau de incerteza. Com uma boa base de dados pode-se prever o resultado de um determinado método de medição, por isso deve-se realizar um grande número de medições.

$\tilde{V}=\left(V_{1}+V_{2}+V_{3}+\ldots+V_{n}\right) n$

Por outro lado deve-se tentar diminuir ao máximo os erros sistemáticos em comparação aos erros aleatórios, os quais não permitem que o tratamento estatístico consiga remover uma tendência que esteja contida nessas medidas.

Para que se obtenha um valor mais próximo do verdadeiro deve-se calcular a média aritmética do conjunto de medidas efetuado, o qual deverá ser bem elevado.

\section{Desvio da Média (d)}

É a média do afastamento de um valor qualquer medido, em relação à média aritmética do conjunto de valores medidos. São expressos por:

$$
\mathrm{d}_{1}=\mathrm{V}_{1}-\tilde{\mathrm{V}} \quad \mathrm{d}_{2}=\mathrm{V}_{2}-\tilde{\mathrm{V}} \quad \mathrm{d}_{3}=\mathrm{V}_{3}-\tilde{\mathrm{V}} \quad \mathrm{d}_{\mathrm{n}}=\mathrm{V}_{\mathrm{n}}-\tilde{\mathrm{V}}
$$

Exemplo: 
Ao fazer uma verificação da lei de Ohm, um grupo de 5 alunos realizou as medidas em que cada um anotou o valor lido do mesmo instrumento e que foram os seguintes:

3,2 A, 3,1 A, 3,2 A, 3,0 A e 3,3 A.

Usando a expressão para calcular o valor médio, mostrada anteriormente, teremos:

$\tilde{V}=(3,2+3,1+3,2+3,0+3,3) / 5=3,16 A$

Calculando os desvios, teremos:

$d_{1}=3,2-3,16=0,04 A$

$d_{2}=3,1-3,16=-0,06 A$

$d_{3}=3,2-3,16=0,04 A$

$d_{4}=3,0-3,16=-0,16 \mathrm{~A}$

$d_{5}=3,3-3,16=0,14 \mathrm{~A}$

Como podemos ver, os desvios podem ser positivos, negativos ou nulos, mas a soma de todos os desvios é igual a zero.

Desvio Médio (D)

Se calcularmos a média dos valores dos desvios médios teremos um indicador da precisão dos instrumentos utilizados no processo de medição. Quanto mais baixo for o valor do desvio médio, mais precisos serão os instrumentos.

A soma dos valores absolutos dos desvios, dividida pelo número de leituras nos dá o valor do desvio médio, ou seja: 
$D=\left(\left|d_{1}\right|+|d 2|+\left|d_{3}\right|+\ldots+|d n|\right) / n$

No exemplo anterior temos:

$D=(0,04+0,06+0,04+0,16+0,14) / 5=0,088 A$

\section{Desvio Padrão ( $\sigma)$}

Quando se analisam os erros aleatórios de forma estatística, o cálculo da raiz quadrada do desvio médio (D). Por definição, a soma de todos os desvios médios individuais, elevados ao quadrado, e dividida por um número infinito de leituras, ao ser extraída a sua raiz quadrada será chamado de Desvio Padrão. É, portanto, expresso como:

$\sigma=v\left(\left|d_{1}^{2}\right|+\left|d_{2}^{2}\right|+\left|d_{3}^{2}\right|+\ldots+\left|d_{n}^{2}\right|\right) / n$

Na prática, o número de medidas será finito e a expressão do desvio padrão passa a ter a seguinte forma:

$\sigma=v\left(\left|d_{1}^{2}\right|+\left|d_{2}^{2}\right|+\left|d_{3}^{2}\right|+\ldots+\left|d_{n}^{2}\right|\right) / n-1$

A maioria dos resultados científicos é apresentada sob a forma de desvio padrão.

\section{Distribuição Normal de Erros}

Se para um determinado experimento fizermos um número $\mathbf{n}$ de leituras de uma grandeza e anotarmos o número de vezes que cada valor ocorreu e expressarmos graficamente esses valores e o número de ocorrências na forma de um histograma, teremos uma curva conhecida como Gaussiana. Quanto mais estreita for a curva, maior será a probabilidade do valor central coincidir com a média aritmética e o valor verdadeiro. 
Seja, por exemplo, um experimento sobre a medida de uma tensão nominal de $110 \mathrm{~V}$, em que foram efetuadas 75 leituras com um voltímetro digital e registradas com uma aproximação de $0,1 \mathrm{~V}$, conforme

\begin{tabular}{|l|c|}
\hline \multicolumn{1}{|c|}{ Tensão (V) } & Número de Leituras \\
\hline 109,6 & 1 \\
\hline 109,7 & 3 \\
\hline 109,8 & 10 \\
\hline 109,9 & 13 \\
\hline 110,0 & 22 \\
\hline 110,1 & 12 \\
\hline
\end{tabular}
mostrado a seguir. 


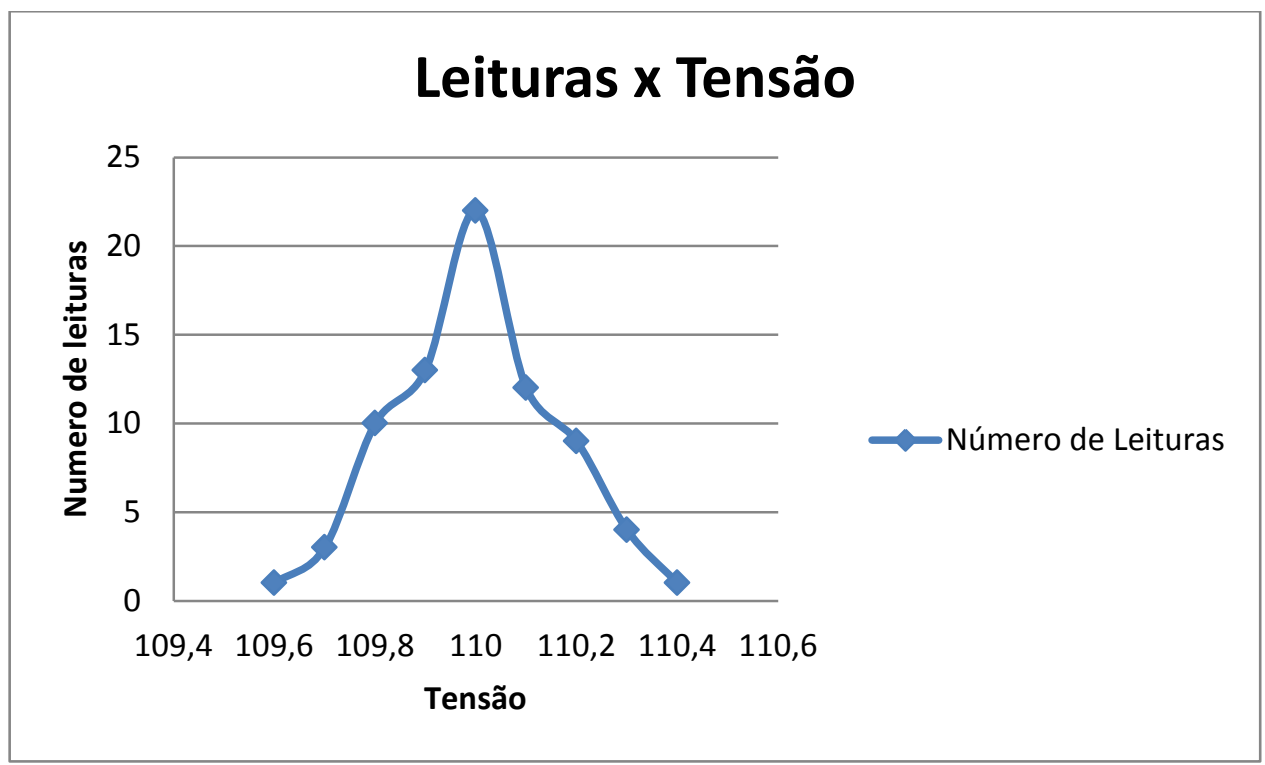

A Gaussiana evidencia que erros pequenos são mais prováveis que erros grandes, os quais são muito improváveis e que a probabilidade de ocorrência de erros positivos ou negativos é semelhante e simétrica em relação a zero. O valor médio da curva será então o valor real da variável medida.

Além disso, as leituras incluem os distúrbios mencionados anteriormente como erros aleatórios.

Na curva feita a partir da tabela acima (histograma) o valor mais provável da grandeza que está sendo medida é o valor central, $110 \mathrm{~V}$.

Suponhamos agora que numa aula de laboratório de Circuitos Elétricos, um grupo de alunos tenha efetuado a medida da resistência de um resistor e que tenham feito um total de dez medidas, utilizando um instrumento digital e, portanto, sem ocorrência de erros de paralaxe ou outro tipo de erro, a não ser os aleatórios.

Valores anotados: $475 \Omega, 472 \Omega, 478 \Omega, 470 \Omega, 473 \Omega, 472 \Omega, 479 \Omega, 472 \Omega, 477 \Omega$ e $472 \Omega$.

Calcular o valor médio e o desvio padrão.

Para facilitar o entendimento colocaremos os dados na tabela a seguir: 


\begin{tabular}{|c|c|c|}
\hline $\operatorname{Medida}(\Omega)$ & Desvio (d) & $d^{2}$ \\
\hline 475 & 1 & 1 \\
\hline 472 & -2 & 4 \\
\hline 478 & 4 & 16 \\
\hline 470 & -4 & 16 \\
\hline 473 & -1 & 1 \\
\hline 472 & -2 & 4 \\
\hline 479 & 5 & 25 \\
\hline 472 & -2 & 4 \\
\hline 477 & 3 & 9 \\
\hline 472 & -2 & 4 \\
\hline$\Sigma=474$ & $\sum|d|=26$ & $\sum d^{2}=84$ \\
\hline
\end{tabular}


